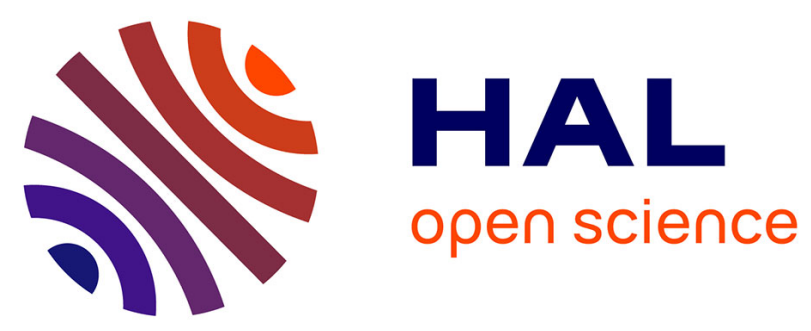

\title{
Interoperability Improvement in a Collaborative Dynamic Manufacturing Network
}

Emna Moones, El Mouloudi Dafaoui, El Mhamedi Abderrahman, Nicolas

Figay, Ali Koudri

\section{- To cite this version:}

Emna Moones, El Mouloudi Dafaoui, El Mhamedi Abderrahman, Nicolas Figay, Ali Koudri. Interoperability Improvement in a Collaborative Dynamic Manufacturing Network. 13th IFIP International Conference on Product Lifecycle Management (PLM), Jul 2016, Columbia, SC, United States. pp.286295, 10.1007/978-3-319-54660-5_26. hal-01699735

\section{HAL Id: hal-01699735 \\ https://hal.inria.fr/hal-01699735}

Submitted on 2 Feb 2018

HAL is a multi-disciplinary open access archive for the deposit and dissemination of scientific research documents, whether they are published or not. The documents may come from teaching and research institutions in France or abroad, or from public or private research centers.
L'archive ouverte pluridisciplinaire HAL, est destinée au dépôt et à la diffusion de documents scientifiques de niveau recherche, publiés ou non, émanant des établissements d'enseignement et de recherche français ou étrangers, des laboratoires publics ou privés. 


\title{
Interoperability improvement in a collaborative Dynamic Manufacturing Network
}

\author{
Emna Moones $^{1,2}$, El Mouloudi Dafaoui ${ }^{2}$, El Mhamedi Abderrahman ${ }^{2}$ \\ Nicolas Figay ${ }^{3}$, Ali Koudri ${ }^{1}$ \\ 1Technological Research Institute SystemX, Palaiseau France \\ \{emna.moones, ali.koudri\}eirt-systemx.fr \\ 2Laboratoire QUARTZ EA 7393 IUT de Montreuil - Université Paris8, \\ 140 rue de la Nouvelle France, 93100 Montreuil, France \\ \{e.dafaoui, a.elmhamedi\}@iut.univ-paris8.fr \\ 3Airbus Group Innovations, 12 rue Pasteur 92150 Suresnes, France \\ nicolas.figay@airbus.com
}

\begin{abstract}
Today, more than ever, enterprise interoperability is a key factor of successful collaboration and exchange of information. It was identified as a critical need that has to be taken into account through the whole life cycle of the manufactured product and an essential property for development and growth. This is particularly significant when it comes to collaborative enterprise networks, like Dynamic Manufacturing Network (DMN), where a distinct group of partners is connected in a chain-like model and where cooperation is crucial to achieve a specific goal. Dealing with interoperability issues in a collaborative DMN, we have to mention the importance of product data and process standards implementation as interoperability enablers. This work seeks to contribute to the improvement of enterprise interoperability along the manufacturing phase of the product in a collaborative DMN. It illustrates the collaboration between the business planning level and the manufacturing level with the implementation of PLM (Product Lifecycle Management) standards. Our added value is to follow a multi-level approach based on the use of standards in a DMN. The proposed approach is highlighted by a manufacturing case study.
\end{abstract}

Keywords: Collaboration, DMN, PLM, Interoperability, Mediator, Standards, Multi-level approach.

\section{Introduction}

The advent of digital technologies has led to stronger competitiveness and demand of products with lower cost, high quality and short delay of production in the industry. In response to this increasing competitiveness and higher demands in terms of services, most of governments are pushing initiatives to foster collaboration among industrial 
partners and with academic partners in order to push innovation and creation of more added values. This requires setting up new organizations with new business models along with suitable methodologies. One way to achieve more efficient collaborations today is to rely on an adaptive platform supporting relevant business rules and models. Such a platform shall provide services allowing the sharing of the right information in the right time and location for the right people. But, the lack of interoperability between Information Systems (IS) is increasingly becoming an issue in the collaboration and cooperation of enterprises. In this paper, we consider the use of open standards as key enablers for providing the required interoperability among the stakeholders involved in the collaboration. The use of open standards defines a common way to exchange data elements with shared syntax and semantics. Open standards ensure consistent management of data beyond technologies and allow harmonization of disparate information shared within the collaboration. There are numerous standards covering data exchange for various domains: ISO STEP ${ }^{1}$ standard for the exchange of product model data, ISA $-95^{2}$ for the integration of enterprise and control systems, XML Process Definition Language (XPDL) ${ }^{3}$ for exchanging business process definitions between different workflow products. Standard exchange and representations of data is not enough to ensure collaboration between organizations and emergence of innovative ideas. In order to improve the collaboration, we need to take into account industrial practices and life cycle issues: versioning, configuration, bug tracking, change requests, and so on. In the end, we need a support for a more holistic approach covering the whole life cycle of the product, from the initial idea to its realization, maintenance and withdrawal. Such an approach is covered by the PLM. Indeed, PLM represents a holistic approach for managing the different phases of the product along with the management of processes as well as physical and logical resources. It allows to support the exchange and the synchronization of information through the different phases of the product's life cycle in order to speed up its development or to improve its quality. The question that arises here is the following: how can we establish and improve the synchronization of information considering the heterogeneity of skills, tools and data when several stakeholders are involved in the collaboration. The Standard and Interoperability PLM (SIP) ${ }^{4}$ project investigates this issue and aims to make collaboration more effective. For this purpose, one of the main objectives of this project is to specify a "test bed" to validate implementations of PLM standards, particularly in the context of a DMN. This paper presents results from the SIP project regarding the manufacturing phase. Those results are illustrated on an industrial case study aiming to improve interoperability between the business planning level, supported by Enterprise Resource Planning (ERP), and the manufacturing operations level, supported by Manufacturing Execution System (MES). In this use case, interoperability between ERP and MES tools is achieved thanks to the integration of the ISA-95 standard. This paper is structured as follow: Section 2 highlights our motivations, Section 3 presents the related works, Section 4 covers the proposed approach, and Section 5 presents the

\footnotetext{
${ }^{1} \mathrm{http}: / / \mathrm{www} \cdot$ steptools.com/library/standard/

2 https://www.isa.org/isa95/

3 http://www.xpdl.org/

${ }^{4} \mathrm{http}: / / \mathrm{www}$.irt-systemx.fr/systemx-lance-le-projet-sip-standards-interoperabilite-plm/
} 
industrial case that illustrate our proposition. Finally Section 6 discusses our proposition and gives some hints for future works.

\section{Motivations}

In order to enhance their competitiveness, companies no longer take ownership of all the assets and processes needed in delivering value to the customer. Instead, they focus on their core competencies and partnerships with companies possessing complementary strengths [1]. This has led to the rise of distributed and flexible manufacturing networks. However, the lack of an agile and responsive management methodology of such structures has hindered them from reaching their full potential. Today, the novel concept of DMN stands out as a cutting-edge solution in this quest, carrying a wide set of assets aiming to drive manufacturing organisations into the new global economy [2]. DMN is defined as a collection of independent companies, possessing complementary strengths and integrated with streamlined material, information, and financial flows that work together to meet market demands [1]. In this context, we need to deal with the issues of information integration and data shared across distributed heterogeneous application systems. For this purpose, we need to build up a high quality information integration platform. Indeed, one of the biggest current research challenges in networked manufacturing is to implement consistently the exchange and sharing of data. One way to improve collaboration in DMN is to improve interoperability, relying on the use of open standards. Ensuring effective and secured collaboration requires preparing and constructing operational interoperability [3]. According to [4], interoperability is defined as "the existence of different actors and systems which realise a collaborative action and the ability to communicate own data for actors which can be similar or radically different and to use these data". Some European research projects, such as ATHENA [5], have dealt with interoperability issues and have led to specifications and implementations of interoperability frameworks. These solutions present some weaknesses, for instance, the Athena Interoperability Framework (AIF) is insufficient for establishing operational interoperability at an acceptable price within a DMN. Moreover, open standards are not considered (e.g. ASD SSG ${ }^{5}$ standards), and many interoperability brakes were not addressed, including testability of interoperability which is addressed by SIP approach [6]. Besides, interoperability remains today a real challenge for enterprises, and some brakes have been identified following the proposed solutions. In this context, our work addresses interoperability issues by suggesting a global approach which aims to deal with several interoperability levels using standards implementation in the whole life cycle of the product. Our goal is to contribute on proposing a solution for interoperability between ERP Information System and MES Information System. The following Section presents some related works to our proposition.

${ }^{5}$ ASD SSG: ePLM Interoperability, http://www.asd-ssg.org/ (2014). 


\section{State of the art}

Nowadays ERP systems have become predominant in medium and large companies [7]. They consist of series of integrated modules dedicated to the management of customers, suppliers and human resources, as well as the management of manufacturing. The goal of an ERP [8] is to support the unification of different departments of the company. To achieve this goal, an ERP relies on an application system. Information managed by an ERP can be used at different levels and for different purposes, e.g. the services of directions production, the customer relations or finance. ERP allows collaborative works between different services of an enterprise thanks to the use of a common interface to communicate and share data. Besides, MES systems are defined by [9] as a set of software and hardware components for the management and optimization of production activities from the launch of the order to the obtainment of the final product. The MES system is responsible for the production plan; it guides, initiates, responds and reports functionalities of the factory in real time. We can notice that these two systems have complementary functions. Some enterprise experiences [10] report that ERP and MES systems are fundamental and shall collaborate together. Indeed, ERP gives a global vision about the manufacturing of the product while MES monitors its production in real time. ERP and MES systems exchange and share information during the manufacturing process. It is therefore important to ensure the quality of collaboration between these two systems. To this end, a common standard for data exchange shall be elected and the ISA-95 standard seems to bridge the gap between ERP and MES systems. Collaboration between ERP and MES requires the use of a mediator ensuring the exchange of information. Indeed, several works have addressed the interoperability issue between IS. The result of those works is that interoperability remains a complex issue. According to [11][12][13] there are three levels of interoperability: conceptual, technological and organizational. Conceptual interoperability deals with the syntactic and semantic compatibilities when exchanging information. Technological interoperability refers to the use of computers or Information and Communication Technologies (ICT) to communicate and exchange information. Finally, organizational interoperability deals with the standard definition of responsibilities and authorities. These three levels are well addressed by the literature. For instance, the authors in [14] propose an holonic approach modeling the manufacturing process of a product. The holonic model is compared with two other standard models: the Unified Enterprise Modeling language (UEML) [15] for the business level supported by an ERP system and the ISA-95 [16] language for the manufacturing level supported by an MES system. The authors of this contribution propose a mapping of several semantics concepts between these two approaches. Contribution in [14] deals with the semantic interoperability between ERP and MES systems. This semantic interoperability issue is also addressed in [17]. This contribution provides a study on the impact of interoperability on the transition between the design and the manufacturing phases of the product. In particular, this contribution considers the value of the interoperability between Product Data Management (PDM), ERP and MES. The proposed approach is based on the use of ontologies related to STEP and ISA-95 standards. In [18], authors address the semantic barriers of the interoperability in achieved works as resulted to the semantic alignment between the ISA standard and 
the SCOR model [19]. In [20], the authors focus on the collaboration between ERP and MES systems. To solve the related issue, their works relies on a model driven approach to support the manufacturing process through models transformations. There are several works aiming to provide solutions to ensure interoperability at both semantic and technical levels. For example [21] proposed a modeling approach based on the STEP standard to deal with the consistent transition between design and manufacturing phases supported by PDM and ERP systems. In the case of point-to-point interoperability, a convertor has to be provided each time a new system is included in the network. Doing so, the number of convertors can increase quickly as the number of partners increases [21]. One way to deal with this complexity is to use a mediator when several partners shall collaborate together. For instance, authors in [22] use a mediator as a software module to exploit encoded knowledge about some sets or subsets of data. This mediator aims to provide relevant information to be consumed by higher layers of applications. The concept of mediators is introduced in [23], and is defined as a component enabling location of information and the solving of schematic and semantic conflicts. The SIP project has implemented a mediator platform as a service simplifying the use and the implementation of PLM standards. The work presented in this paper is one of the results of the SIP project, which relies on the use of PLM standards to deal with interoperability issues in the manufacturing phase between ERP and MES systems. Compared to the related works introduced before that address the interoperability only at semantic and technical levels, we propose to consider the interoperability issue from an holistic perspective, taking into account all interoperability levels. Our approach implements the ISA-95 standard which is the standard of integration between ERP and MES systems. Table 1, summarizes our position according to existing approaches.

Table 1. Position according to the state of the art.

\begin{tabular}{lccccccccccc}
\hline Approache & T & S & O & MD & Ont & IS & STEP & N & I & ERP/ME & Other \\
S & I & I & I & A & o & A & & S & I & S & S \\
\hline$[14]$ & N & Y & N & Y & N & Y & N & N & N & Y & N \\
{$[17]$} & $\mathrm{Y}$ & $\mathrm{Y}$ & $\mathrm{N}$ & $\mathrm{N}$ & $\mathrm{Y}$ & $\mathrm{Y}$ & $\mathrm{Y}$ & $\mathrm{N}$ & $\mathrm{N}$ & $\mathrm{Y}$ & $\mathrm{Y}$ \\
{$[18]$} & $\mathrm{N}$ & $\mathrm{Y}$ & $\mathrm{N}$ & $\mathrm{Y}$ & $\mathrm{Y}$ & $\mathrm{Y}$ & $\mathrm{N}$ & $\mathrm{N}$ & $\mathrm{N}$ & $\mathrm{N}$ & $\mathrm{Y}$ \\
{$[20]$} & $\mathrm{Y}$ & $\mathrm{N}$ & $\mathrm{N}$ & $\mathrm{Y}$ & $\mathrm{N}$ & $\mathrm{N}$ & $\mathrm{N}$ & $\mathrm{N}$ & $\mathrm{N}$ & $\mathrm{Y}$ & $\mathrm{N}$ \\
{$[21]$} & $\mathrm{Y}$ & $\mathrm{Y}$ & $\mathrm{N}$ & $\mathrm{N}$ & $\mathrm{N}$ & $\mathrm{N}$ & $\mathrm{Y}$ & $\mathrm{N}$ & $\mathrm{N}$ & $\mathrm{N}$ & $\mathrm{Y}$ \\
Our & $\mathrm{Y}$ & $\mathrm{Y}$ & $\mathrm{Y}$ & $\mathrm{Y}$ & $\mathrm{N}$ & $\mathrm{Y}$ & $\mathrm{N}$ & $\mathrm{N}$ & $\mathrm{Y}$ & $\mathrm{Y}$ & $\mathrm{N}$ \\
approach & & & & & & & & & & & \\
\hline
\end{tabular}

TI: Technical Interoperability, SI: Semantic Interoperability, OI: Organizational Interoperability, Onto: Ontologies, NS: No Standard, II: Interoperability Improvement N: No, Y: YES.

In the following sections, we will explain the proposed approach illustrated by a case study in order to improve interoperability between business and manufacturing levels.

\section{$4 \quad$ Proposed approach}


As mentioned in the previous section, point-to-point integration does not represent an adequate solution to foster collaboration between industrial partners. There is an imperative need to provide interoperability between these organizations supported by widely adopted standards. Consequently, the SIP methodology aims at validating implementation of a set of coherent PLM standards. One of the main objectives of the SIP project is to provide an innovative interoperability framework (shown in Fig. 1) based on a model-driven methodology. The main outcome of this framework is the development of "test beds" to assess the implementation of PLM standards. This framework conforms to the TOGAF standard and its implementation relies on the Archi tool which supports the Archimate language [16]. In this way, we propose a multi-level approach as mediators using different tools adopted by the SIP methodology Fig. 1.

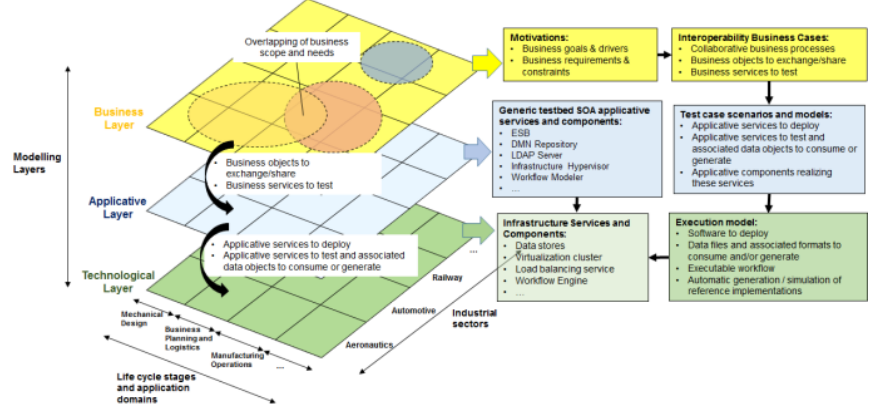

Fig. 1. Conceptual levels of Archimate modeling

Fig. 1 illustrates our approach to improve interoperability between ERP and MES systems following the different levels of interoperability and different layers of representation using a top-down way. To deal with the different interoperability issues presented in the previous section, in Fig. 2, we map the discussed interoperability levels with layers of the Archi framework. This multi-level approach allows us to address all interoperability brakes mentioned in the related work. The first step of our approach is to model the collaborative business scenario supported by both ERP and MES systems, and covered by the ISA-95 standard. The second step of the approach is to model the application including business functions. The last step consists in modeling the technical layer supporting the exchange of information, mainly through the use of XML technologies. Those steps are detailed in the following paragraphs.

First Step. The organizational interoperability is addressed thanks to the use of an MDA methodology. The outcome of this step is a model capturing the functions of business planning, the functions of manufacturing and finally the functions providing a support for ISA-95 standard. We have discussed the values of this level in a previous work [16]. Indeed, in [16] we demonstrated how the use of enterprise architecture modeling languages could contribute to better specify and prepare interoperability business cases.

Second Step. Business and planning functions modeled in the previous step are refined in this step. At the end, business planning information shall be accessible for both ERP and MES solutions. This layer deals with semantic interoperability between ERP and MES systems. ERP and MES concepts are captured by meta-models and common concepts are compared in order to provide support for their semantic 
alignment. These meta-models are then instantiated to provide concrete data capturing production schedule and Manufacturing Bill of Material (MBOM). These models are then compared to ISA95 models conformant to the "Part2" of the standard in order to measure the gap between the ERP and the MES systems.

Third step. The technical interoperability is supported by a connector playing the role of a mediator. It covers XML data extracted from the ERP solution to the standardized XML format of ISA-95 which is the Manufacturing Markup Language (B2MML). The structure of the connector is illustrated in Fig. 3. It relies on an Extensible Stylesheet Language Transformation (XSLT) to specify the transformation rules. B2MML is an XML implementation of the ISA-95 standard providing a common XML data structure to be exchanged by ERP and MES vendors. The specification of the B2MML schema in XSD complies the ISA-95 standard.

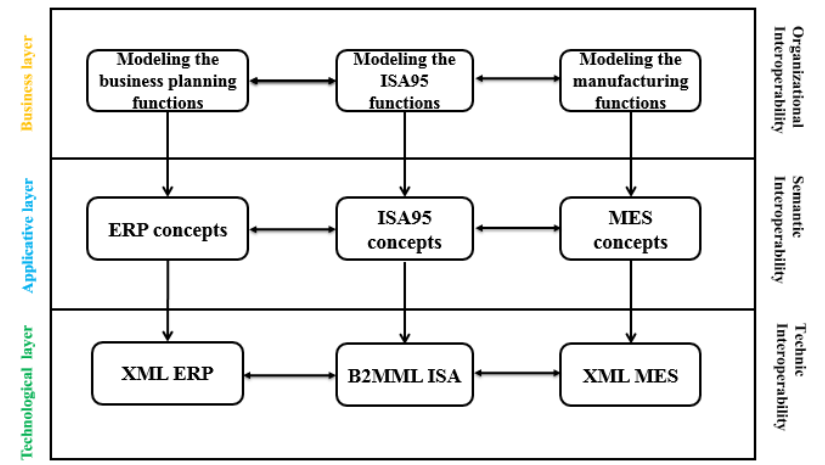

Fig. 2. Position relative to interoperability and framework levels

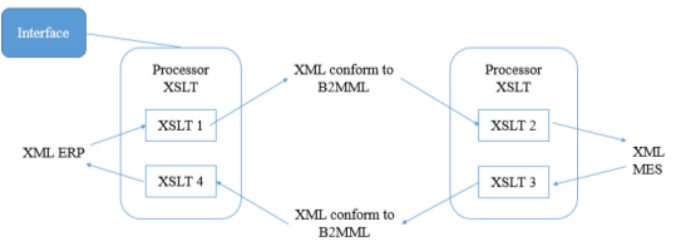

Fig. 3 . Structure of XML/B2MML connector.

The added value of our connector consists in a more global integrated approach between business and manufacturing aspects. This connector is available on the SIP platform and can be used to test the consistency of ISA-95 standard implementations.

\section{Case study}

DEKENZ $^{6}$ is a French company specialized in the development, the fabrication and the marketing of pens. The objective of this approach is to provide to universities a very

${ }^{6}$ DEKENZ website: http://pm.flamant.free.fr/dekenz/?p=accueil 
concrete application. The production of every pieces and their integration is performed by students at "La Halle Technologique" of the "IUT Montreuil"?. In [16], we dealt with the modeling of the ERP-MES data integration scenario of the DEKENZ case study. For this paper, we emphasize the exchange of MBOMs from the ERP system to the MES system. In order to do so, we convert the information extracted from the ERP to the ISA95 standard. For this purpose, we use the ODOO ${ }^{8}$ ERP solution, which is a suite of open core enterprise management applications supporting billing, accounting, manufacturing, purchasing, warehouse management and project management. Practically, we start by extracting the XML file describing the MBOM from ODOO solution and we convert it to the B2MML format.

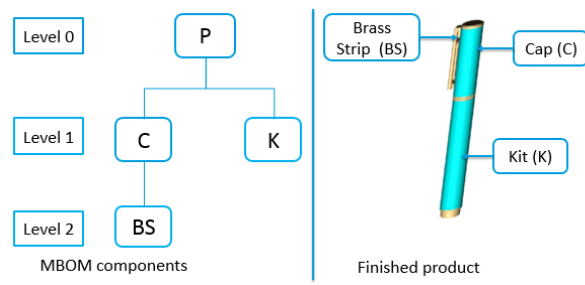

Fig. 4. Simplified DEKENZ MBOM

The resulting MBOM is composed of three levels: at the highest level (level 0) describes the Pen (P) composed by a Kit $(\mathrm{K})$ and a Cap $(\mathrm{C})$ in level 1. A Brass Strip (BS) is a component of the Cap at the lowest level. We capture this information in the MBOM file. We extract then the MBOM into an XML file conformant to the ERP data model. The next step is to convert the extracted information into the B2MML standard. The mapping between the concepts expressed XML ODOO ERP and the standardized B2MML format is presented in Table 2. The limit of this approach is that the mapping is performed manually by linking the concepts according to their semantic meaning.

Table 2. Correspondence between XML ODOO MBOM and B2MML ISA-95 MBOM.

\begin{tabular}{ll}
\hline XML ODOO & B2MML ISA95 \\
\hline Bill of Material & Product definition \\
External ID & ID \\
Article Name & Description \\
Range Name & Equipment specification \\
Range charging post name & Equipment specification description \\
Line BOM article name & Material specification \\
Valid from & Duration \\
Valid until & Duration \\
Quantity article & Quantity \\
\hline
\end{tabular}

\footnotetext{
7 IUT Montreuil website : $\underline{\text { http://www.iut.univ-paris8.fr/ }}$

8 https://www.odoo.com/fr_FR/
} 
This work has been developed through an internship, and is reported with more details in [24], and a first connector converting the XML information extracted from the ERP solution into the B2MML format according to the standard ISA-95 has been provided (Fig. 5).

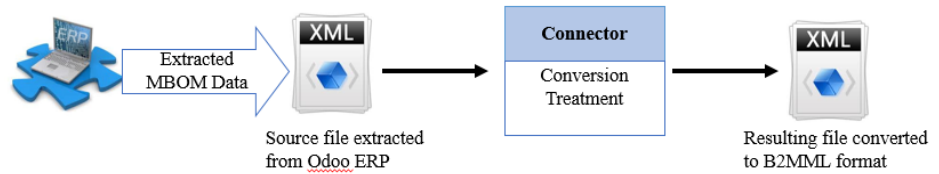

Fig. 5. Global architecture of the connector

\section{Conclusion and Future Works}

Enterprise applications need to be interoperable in order to achieve a seamless business integration across organizational boundaries in a DMN. This paper summarizes our approach to deal with interoperability issues between ERP and MES in a DMN. Our added value is to support a multi-levels approach based on the use of standards in a DMN. In addition to existing approaches, we support the technological level of interoperability. The approach is illustrated by a case study on an application from DEKENZ. Through our experimentation, we were able to simulate the collaboration. We have used the SIP "test bed" facilities to demonstrate the interest of using models to prepare, build, verify and validate enterprise interoperability. In future works, we will address the applicative and business level to enhance the proposed framework with functionalities like the simulation of the dynamic inclusion or exclusion of enterprises in the network. As manufacturing and engineering organizations become more and more globalized, the capability of simulating and monitoring accurately the operation of dynamic alliances at a very early stage becomes increasingly important. Our future research will investigate an innovative approach to assess enterprise interoperability in a DMN context.

Acknowledgments. This research work has been carried out under the leadership of the Technological Research Institute SystemX, and therefore granted with public funds within the scope of the French Program "Investissements d'avenir".

\section{References}

1. N. Viswanadham and Roshan S. Gaonkar: Partner Selection and Synchronized Planning in Dynamic Manufacturing Networks. IEEE Trnasactions Robot. Autom. 19, 117 - 130 (2003).

2. Ourania Markaki, Dimitrios Panopoulos, Panagiotis Kokkinakos, S.K.: Towards Adopting Dynamic Manufacturing Networks for Future Manufacturing: Benefits and risks of the IMAGINE DMN End-toEnd Management Methodology. Worshop on Enabling Technologies: Infrastructure for Collaborative Enterprises WET ICE. IEEE.

3. Morris, E., Levine, L., Meyers, C., Place, P., Plakosh, D.: System of Systems 
Interoperability (SOSI): final report (No. CMU/SEI-2004-TR-004). Carnegie-Mellon Univ Pittsburgh Pa Softw. Eng. Inst. (2004).

4. Daclin, N., Chen, D., Vallespir, B.: Développement de 1' interopérabilité des applications de gestion industrielles : concepts de base et définitions. Presented at the (2005).

5. ATHENA: Interoperability Framework v2.0 - NEHTA. "Interoperability Framew. v2.0." (2007).

6. Figay, N.: Interoperability of Technical Enterprise Application, (2009).

7. Bernard Grabot, Anne Mayére, I.B.: ERP Systems and Organisational Change: A Sociotechnical Insight. (2008).

8. J. Michael Tarn, David C. Yen, M.B.: Exploring the rationales for ERP and SCM integration. Ind. Manag. Data Syst. 102, 26-34 (2002).

9. Barkmeyer, E., Denno, P., Feng, S., Jones, A., Wallace, E.: NIST Response to MES Request for Information. 0, 1-24 (1999).

10. Origin, A.: «La convergence entre MES et ERP favorise le partage des indices de performances ». 17-18 (2009).

11. Chen, D.: Enterprise Interoperability Framework. EMOI INTEROP (2006).

12. Johan Ullberg, David Chen, P.J.: Barriers to Enterprise Interoperability. Presented at the (2009).

13. EIF: White Paper "European Interoperability Framework ." 40 (2004).

14. BAÏNA, S.: INTEROPERABILITE DIRIGEE PAR LES MODELES : Une Approche Orientée Produit pour l'interopérabilité des systèmes d'entreprise. 204 (2006).

15. L, L.C.U.E.M., Vallespir, B., Vallespir, B., Braesch, C.: L'Intégration en Modélisation d' Entreprise : Les chemin d'UEML. Presented at the (2003).

16. Moones, E., Vosgien, T., Kermad, L., Dafaoui, E.M., Mhamedi, A. El, Figay, N.: PLM standards modelling for enterprise interoperability: A manufacturing case study for ERP and MES systems integration based on ISA-95. 6th International IFIP Working Conference on Enterprise Interoperability (IWEI 2015) - See more at: http://iwei2015.mines-ales.fr/\#sthash.28fjHInQ.dpuf (2015).

17. Tursi, A., Tursi, A., Nancy, I., Tursi, A.: Ontology-Based approach for Product-Driven interoperability of enterprise production systems, (2009).

18. Sakka, O., Boucher, X., Goepp-thiebaud, V., Maret, P.: Alignement sémantique entre référentiels d' entreprise - Application aux systèmes d' ex écution de la fabrication ( MES ). (2012).

19. Version, S.: Supply-Chain Operations MAKE DELIVER RETURN Supply-Chain Operations Reference-model.

20. Auzelle, J.: d ' un syst 'eme d ' information en entreprise centr ' e sur le produit Thèse Docteur de 1' Université Henri Poincaré, Nancy I. (2009).

21. Paviot, T.: Méthodologie de résolution des problèmes $d$ ' interopérabilité dans le domaine du Product Lifecycle Management, (2010).

22. Wiederhold, G.: Mediators in the Architecture of Future Information Systems. IEEE Comput. 25, 38-49 (1992).

23. Jouanot, F.: Un modèle sémantique pour 1 ' interopérabilité de systèmes d' information.

24. Ben Salah, M.: Etude de l'interopérabilité technique dans le PLM: Application à un cas d'échange ERP/MES. (2015). 